(C2018, Elsevier. Licensed under the Creative Commons Attribution-NonCommercialNoDerivatives 4.0 International http://creativecommons.org/about/downloads

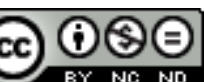




\title{
WILLINGNESS OF PEOPLE WITH MENTAL HEALTH DISABILITIES TO TRAVEL IN DRIVERLESS VEHICLES
}

\author{
Roger Bennett $^{\mathrm{a}^{*}}$ Rohini Vijaygopal ${ }^{\mathrm{b}}$, and Rita Kottasz $\mathrm{z}^{\mathrm{a}}$
}

${ }^{a}$ Kingston University Business School, Kingston University London, Kingston Hill, Kingston-Upon -Thames, KT2 7LB.

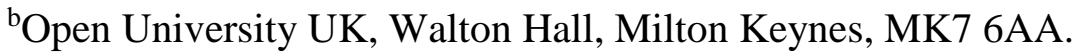

Email: r.bennett@kingston.ac.uk

rohini.vijaygopal@open.ac.uk

rita.kottasz@kingston.ac.uk

*Contact: Dr Roger Bennett, Kingston University Business School, Kingston Hill, KingstonUpon -Thames, KT2 7LB. Email: r.bennett@kingston.ac.uk. 


\section{WILLINGNESS OF PEOPLE WITH MENTAL HEALTH DISABILITIES TO TRAVEL IN DRIVERLESS VEHICLES}

\section{Structured Abstract}

\section{Introduction}

The purpose of the research was to examine possible barriers to the use of autonomous vehicles (AVs) perceived by people with intellectual disabilities. Access to user-friendly and equitable transportation is a major factor influencing the health and well-being of people with mental disabilities, and AVs have much to offer to intellectually vulnerable travellers. It is important therefore to determine the factors that will encourage mentally disabled people to travel in driverless vehicles.

\section{Methods}

A Structural Topic Modelling (STM) approach was employed to analyse 177 responses of mentally disabled people to an open-ended question concerning their willingness to travel in an AV. Outcomes to the STM, together with data on the sample members' levels of internal locus of control, generalised anxiety, age, gender, prior knowledge of AVs, and the intensity of an individual's disability were then incorporated into a structural equation model constructed to relate attitudinal topics identified by the STM to the participants' willingness to travel in AVs.

\section{Results}

Three categories of attitude towards AVs arose from the STM; respectively involving freedom, fear and curiosity. Two of the three attitudinal topics, freedom and fear, significantly predicted the participants' willingness to use driverless vehicles. The "freedom" topic was significantly explained by generalised anxiety, intensity of disability, and prior knowledge of AVs. Topic two ("fear") depended significantly on generalised anxiety and prior knowledge, and also on locus of control and (female) gender. The third topic (“curiosity") was influenced by locus of control and prior knowledge.

\section{Conclusion}

The results of the study offer a template for government agencies and vehicle manufacturers to apply when formulating public information campaigns promoting the acceptance of driverless vehicles by intellectually disabled people. Public information campaigns targeted at this important segment of the population should incorporate messages based on factors known to affect mentally disabled people's attitudes towards autonomous vehicles.

Key words. Autonomous vehicles, mental health, structural topic model, locus of control, generalised anxiety disorder, public information campaigns. 


\section{HIGHLIGHTS}

- Examines intellectually impaired people’s concerns regarding autonomous vehicles.

- Applies a semi-automated qualitative research method.

- Suggests antecedents and consequences of mentally disabled people's attitudes towards AVs.

- Identifies main points for inclusion in public information campaigns.

- Argues for consideration of mentally disabled people's views when creating AV transportation policies.

\section{INTRODUCTION}

\subsection{Transportation and the Mentally Impaired}

Transportation is known to represent a serious problem for intellectually disabled people (Tanzman, 1993; Loxe, 2017; Butcher 2018); with negative impacts on their abilities to socialise, attend hospital appointments, go shopping, remain in employment, and generally interact with local communities. A consequence is that many people with intellectual disabilities (see end note 1) travel less frequently than others (MHF, 2015). Lack of mobility may result in less access to health care, in loneliness and psychological isolation, loss of selfworth, and a sense of entrapment i.e., of "being a prisoner in one's own home” (MHAG, 2011 p.2) that causes stress and may worsen a person's mental health condition (Claypool et al., 2017; Doray and Burke, 2018; Garrido-Cumbrera, Ruiz, Brace and Lara, 2018).

This article explains how the introduction of driverless cars (autonomous vehicles [AVs]) will affect and improve the transportation experiences of people with intellectual impairments. In particular, the advent of AVs will make available far wider and more convenient transportation opportunities to intellectually impaired people who at present cannot, or voluntarily do not, drive (Bradshaw-Martin and Easton, 2014; Chapman, 2016; Doray and Burke, 2018) (see end note 2). Vehicle manufacturers plan to market AVs from 2021 onwards (Gora and Rub, 2016; Herrmann, Brenner and Stradler, 2018), and the governments of several countries (including the UK) have expressed their desire that most of the vehicles on their roads be driverless by 2040 (Oldham, 2016). (It is relevant to note in the present connection that by 2040 the "family car" will be a driverless vehicle for nearly all family units.) Many intellectually disabled individuals will be in a position to lease or purchase an AV. However, intellectually disabled people may experience special transportation problems relating to their use of AVs that could require assistive technology (Alves, 2017; Nakamura and Ooie, 2017). Examples include possible difficulties with (i) boarding and exiting a vehicle, (ii) operating safety devices within the vehicle, (iii) stopping the vehicle, (iv) moving around inside the vehicle, and (v) selecting a route and destination and establishing how and where to park (Alaribi, 2015; Nakamura and Ooie (2017). Clear signage within a vehicle may be required together with controls of minimal complexity, simple user interfaces, buzzer touch switches, and single button start/stop devices (Claypool, Bin-Nun and Gerlach, 2017). 
With or without a driving licence, most people with intellectual disabilities will use public transport, regularly or occasionally. Public transport can be challenging for people with mental disabilities due to overcrowding, uncooperative staff (who typically will not have been trained on how to communicate with mentally disabled people [Gupta and Cope, 2016]), unreliability, and ignorance and discrimination on the part of fellow travellers (OECD, 2009). Indeed, according to Gupta and Cope (2016), "public transport can send people with a mental disability into a spiral of despair" (p.6). It may be, therefore, that many intellectually disabled individuals who at present do not drive will benefit from obtaining their own AV in preference to continuing to use public transport. It is relevant to note in this connection that many intellectually disabled people also have physical disabilities and/or other health problems that qualify them for state financial mobility allowances, which can be used as part (in severe cases full) payment for the lease of a vehicle (MHF, 2017). According to one national survey, $46 \%$ of all UK people with an intellectual impairment also have a physical disability, and 33\% of all UK residents with a chronic disability have some sort of mental health problem (MHF, 2015).

Another reason for the possible future appeal of AVs to intellectually disabled people is that, consequent to mass production, AVs should be cheap compared to conventional vehicles given the former's simple construction (Alves, 2017). Cortright (2016) reported the cost reduction estimates of several manufacturers, which suggested that by 2040 the current passenger vehicle cost of between US\$1.0 and \$0.83 per mile will fall to between $\$ 0.33$ and $\$ 0.15$ per mile. Affordable and ready access to easy-to-use transportation has been described as a "missing link" to a better life for most intellectually impaired individuals (MHAG, 2011 p.3), especially vis-à-vis the avoidance of social exclusion (DoH, 2011). It is relevant to note, moreover, that lower costs of transport will be particularly advantageous to disabled people in lower-income countries, and also to individuals in higher-income nations who receive state disability payments given that less of their benefit income will be spent on transport, thus enabling them to spend more on other activities.

Yet, despite these positive considerations several factors might cause people with intellectual disabilities to experience deep concerns about using AVs. Examples of possible reservations include fears of being alone, stranded and helpless following a collision (Easton, 2014) and concerns about not knowing how (i) to escape from a damaged vehicle (Chapman, 2016), (ii) to communicate with others and obtain information after an accident, (iii) to arrange for a damaged vehicle to be removed for repair or scrappage, or (iv) to get home after an accident (Claypool et al., 2017; Halsey, 2017; Doray and Burke, 2018).

\subsection{Background to the Study}

As part of its AV prototype development operations, a leading international automotive manufacturer examined user attitudes towards AVs among various groups of transport users, including people with disabilities. With this company's (non-financial) support and with the assistance of (i) an international charity that provides help to all types of disabled people, including the mentally disabled, and (ii) a UK charity which supports intellectually handicapped people in the South East of England, the authors completed studies of attitudes towards AVs and willingness to travel in AVs among UK people with disabilities. A separate investigation was necessary to establish the views of individuals with intellectual disabilities 
because research involving people with intellectual impairments requires certain interviewing techniques and specially adapted research instruments (see Nind, 2008). Hence a study of the views of AVs held by a sample of 177 intellectually disabled individuals was completed.

Although surveys of the views of the general public regarding AVs have been completed, none have explored the perspectives held by disabled people. Surveys of the general public (e.g., Payre, Cestac and Delhomme, 2014; Bazilinskyy, Kyriakidis and de Winter, 2015; Haboucha, Ishaq and Shiftan, 2017; Morris; 2017) have found that, on the average, about half of all sample members were in favour of AVs but that many were strongly against. Payre et al. (2014) concluded that $66 \%$ of a sample of 421 French drivers had positive attitudes to AVs, although this figure varied substantially according to travel context (e.g., if a person had been drinking alcohol). Conversely, an international survey of 8862 people completed by Bazilinskyy et al. (2015) found that only $29 \%$ of the sample could be classified as having a positive attitude to AVs and that $18 \%$ had negative attitudes. Haboucha et al's study of 721 US and Israeli drivers revealed that at least $44 \%$ of the sample had severe hesitations about using an AV. A report authored by Merge Greenwich (2018) (a consortium led by Ford Motor Company, Addison Lee and other interested parties) also noted widespread apprehension among travellers concerning AVs. So far as the general public is concerned, therefore, "the widespread acceptance and hence adoption of this new technology is far from certain” (Konig and Neumayr, 2017 p.42).

\subsection{Aims and Significance of the Research}

The study addressed three main questions: (i) what are the main dimensions of intellectually disabled people's current views regarding AVs, (ii) what factors might determine these views, and (iii) how do attitudes towards AVs relate to an intellectually impaired person's willingness to travel in AVs? Researching these questions is important both for manufacturers wishing to sell or lease their AVs to intellectually impaired people and for governmental state agencies that shortly will need to begin planning the orderly introduction of AVs. The number of UK people with intellectual impairments is substantial (for details see DWP [2018a]). An estimated 1.9 million residents have an intellectual disability (this figure including around 1.1 million individuals with a learning disability (see end note 1). Twentyeight per cent of all UK people with a reportable disease have an intellectual disability, compared to cancer which accounts for $16 \%$ and heart disease which is responsible for $16 \%$ (see MHF [2015]; NHS [2018]). This section of the UK population has a discretionary spending power double that of the teenage market (Vogel, 2006; DWP, 2017), and includes not just intellectually disabled individuals themselves, but also their parents, partners, and possibly other relatives.

State transportation agencies need to be aware of the views of this population segment, because state agencies will have to devise (i) road traffic systems, rules and regulations and technical standards for AVs, and (ii) road layouts capable of accommodating AVs, and matters pertaining to intellectually disabled people need to be taken into consideration. Also, since AVs constitute a new "assistive technology", governments are obliged under Article 20 parts (a) to (c) of the United Nations Convention on the Rights of Persons with Disabilities (UNCRPD) to "take effective measures to facilitate the mobility of persons with disabilities in the manner and at the time of their choice and - - - to facilitate access by persons with 
disabilities to quality mobility aids, devices, and assistive technologies, and to encourage entities that produce assistive technologies to take into account aspects of mobility for persons with disabilities”. Article 12 of the Convention demands that intellectually disabled people have the right to take independent decisions (possibly with support) about how, when and where they travel. A further justification for undertaking research in the area is that, apart from the fact that mentally disabled people represent a significant section of the population, it is, in the words of Tuffrey-Wijne, Bernal and Hollins (2008), "unethical to exclude people with mental disabilities from studies that could provide insight into their experiences and thus help provide better care for them in the future” (p.188).

\subsubsection{Structure of the Paper}

The remainder of the article is structured as follows. Firstly, the composition of the sample is outlined and the research method (structural topic modelling followed by the estimation of a structural equation model) applied to the investigation is described, including the special procedures necessary when researching people with mental impairments. The independent and dependent variables used in the study are specified and discussed, and the ways in which they were measured are detailed. A results section is followed by a conclusion, discussion, and suggestions for future research in the area.

\section{MATERIALS AND METHODS}

\subsection{The Sample}

The study was based on a sample of 177 intellectually disabled UK residents, 54\% of whom had a learning disability, sometimes in conjunction with other mental health issues. All 177 of the sample members had received and/or were currently experiencing some form of medical intervention. However, the precise nature of a person's mental disability was not explored in detail due to sensitivities associated with some forms of mental disability, e.g., those related to substance abuse, eating disorders, post-traumatic stress, or abuse experienced in childhood. Forty-five per cent of the participants had a physical disability as well as an intellectual impairment. All the sample members had "mild to moderate" intellectual impairments "vis-à-vis standard classifications (see Kalave and Forness, 2000; Alaribi, 2015), meaning that they were able to live independently with limited support but were likely to find it harder to learn new skills and to have problems with reading, writing, or personal self-care. Many people in the mild to moderate intellectual impairment category lead relatively "normal" lives and "maintain their reason and ability to function personally and professionally for most of the time" (Hirschman and Stern, 1998 p.426), requiring support only in specific areas (OECD, 2009; DoH, 2011). Tanzman's (1993) review of 26 studies of mentally disabled consumers found that mentally impaired individuals consistently preferred to live in their own dwelling, either alone or with a partner.

Members of the sample were drawn from two sources: (i) a charity that provides assistance to disabled people (including the mentally impaired) and which operates in India, the USA and the UK, is expanding internationally, and is an accredited organisation of the United Nations 
Committee on the Rights of Persons with Disabilities (UNCRDP), and (ii) a charity established in the 1960s to help disabled people in the South East of England. The charity offers residential accommodation, operates several charity shops and drop-in centres, and has an extensive outreach programme. In both organisations, participants were approached via volunteers at the charity. Thirty-eight per cent of the participants had a driving licence (compared to $55 \%$ for the UK population as a whole) and $44 \%$ were in full-time employment (compared with the all-UK figure of 84\%). The basic characteristics of the sample members are given in Table 1.

\section{INSERT TABLE 1 HERE}

\subsubsection{Researching the Mentally Disabled}

As the study involved mentally impaired individuals who might have been vulnerable to stress and other negative emotions during their participation in the investigation, special research procedures were applied. A number of issues arise when questioning intellectually disabled people, who may have poor language skills, deficits in abstract thinking or memory problems, be prone to subjectivity or social desirability influences, or might have limited social experience leading to a tendency to exaggerate. Nevertheless, research has established that "people with mild and moderate learning (intellectual) disabilities are able to self-report reliably when modified questions are used" (Ross and Oliver, 2003, p. 86). In the present study the volunteers asking the questions knew the respondents well and, ipso facto could assess whether the interviewee was able to give informed consent and to appreciate the nature of the study. The volunteers would ensure that the participants were aware of the option to withdraw at any time, would know how to speak slowly and politely and to use repetitions during iterations, would make simple presentations of requests for information, and through training and experience, would be tactful, sympathetic and respectful to the interviewee. Accordingly, the study met the ethical criteria conventionally applied to investigations involving the mentally disabled (Nind, 2008; NDA, 2009). The study was approved by the research ethics committees of the authors' universities.

\subsection{Research Method}

The investigation was based on the participants' responses to a single open-ended request for the participant to "tell me (the interviewer) about all the things that come into your mind when you think about driverless vehicles”. If necessary, the volunteers administering the survey would explain in a few words the meaning of "self-driving vehicle". The volunteers wrote down the reply or had the reply recorded on the volunteer's mobile phone. Participants then completed a short questionnaire. Structural topic modelling (STM) software was used to analyse the responses to the open-ended question (Roberts et al., 2014; Roberts, Stewart and Tingley, 2018). STM enables a researcher to identify latent structures within responses to an open-ended question. Importantly, it also allows the incorporation of covariates into an analysis. The STM algorithm examines the co-occurrence of words across responses and assigns words to topics defined by the homogeneity of the participants' comments within each topic. Consequent to the pre-specification of a specific number of topics the software 
computes "topic prevalence" figures, i.e., the extents to which a participant's response belong to each topic, e.g., $15 \%$ to topic one; $30 \%$ to topic two, etc.; the percentages summing to 100 . The model is computed for various numbers of topics and the most coherent solution in terms of internal homogeneity and the greatest level of discrimination is selected (see Roberts et al., 2014). No coding scheme is necessary since topics emerge from data and are not predetermined. Topic prevalence figures can be aggregated across individuals and related to the sample members' personal characteristics. The most frequent and important words arising in relation to each topic and the most representative comments may be extracted. Topic prevalence figures for each participant can then be employed as the dependent variable in regressions with the participants’ personal characteristics as independent variables.

\subsection{The Covariates}

Following the open-ended query, the participants answered a number of questions (suitably crafted for use with intellectually disabled people) relating to certain covariates that literature in the disability and transportation fields suggest might affect their attitudes to AVs. The covariates considered are 'generalised' anxiety, locus of control, prior knowledge or awareness of AVs, age, gender, income situation, and the effects of the presence of other disabilities. Each covariate is described below.

\subsubsection{Generalised Anxiety}

The term "generalised anxiety" describes the condition whereby people constantly feel anxious about a wide range of situations and issues rather than one specific event (NHS, 2018). It is known that people with intellectual disabilities are particularly vulnerable to generalised anxiety (Reid, Smiley and Cooper, 2011; Sherva and Bakala, 2018). Individuals with the condition find it difficult to control their worries, which can be excessive, irrational, and may interfere with a person's daily life (Spitzer, Kroenke and Williams, 2006). Special scales have been developed to measure generalised anxiety among intellectually disabled people (e.g., Matson, Gardner, Coe and Sovner, 1991; Wehmeyer (1993); Mindham and Espie, 2003). These scales present respondents with simplified queries about their anxious feelings.

Gosling (2017) observed that “anxiety permeates the automotive transportation system”, given that "the automobile is an unsafe space in itself" (p.68) which exposes a person to risk. Anxieties relating to transportation have often been noted among intellectually disabled people (Cooray and Bakala, 2005; NHS, 2015; MHF, 2018), and can be severe (Anxiety UK, 2018). Symptoms of transportation anxiety include feelings of nervousness and discomfort (even dread) while travelling in a vehicle, of panic and of not being in control (Robertson, 2003).

\subsubsection{Locus of Control}

Locus of control (LoC) refers to “an individual's expectations of the capacity to control events, environments or outcomes (Rotter, 1966). High “internal” LoC relates to the belief 
that events and outcomes are determined by effort and ability and not by chance or external factors. Research has established that internal LoC can exert powerful influences on the thoughts and behaviour of intellectually disabled people (see Wood and Letak, 1982;

Wehmeyer, 1993; Shopren, Bovaird, Palmer and Wehmeyer, 2010). The construct is relevant in the present context considering its known connections with (i) intention to use AVs (Payre, Cestac and Delhomme, 2014), (ii) attitudes and behaviour in travel and safe transportation contexts (Özkan and Lajunen, 2005; Huang and Ford, 2012), and (iii) health and personal safety perceptions and activities (Chiteji, 2010). Importantly, a person's level of internal LoC can affect the degree of stress experienced in transport situations (Navaco, Stokols, Campbell and Stokols, 1979; Park, Faulkner and Schaller, 2003). People with high internal LoC, according to Huang and Ford (2012), perceive the dangers road travel more acutely and "tend to attribute driving outcomes to controllable factors and are more likely to take precautionary measures” (p.38). LOC has moreover been found to affect willingness to use new technologies (see McElroy, Hendrickson, Townsend and DeMarie, 2007).

\subsubsection{Knowledge / Awareness of AVs}

This variable is relevant because intellectually disabled people may have been exposed to information about AVs through television programmes, newspaper or magazine articles, or conversations with others. Hence, their attitudes towards AVs may have been formed in part through these contacts (cf. Moons and De Pelsmacker, 2012; Rezvani, Jansson and Bodin, 2015). Research has found that prior knowledge of an automotive product can be a critical determinant of how individuals organise, interpret and explain their thoughts about the product (Egbue and Long, 2012; Rezvani et al., 2015). Prior knowledge might influence an intellectually disabled person's expectations of the characteristics of AVs (cf. Soderlund and Gunnarsson, 2000). Thus, prior knowledge could affect attitudes towards AVs and an individual's feelings of self-confidence when considering their use. It is relevant to note that prior knowledge of AVs might cause a person to dislike them.

\subsubsection{Age, Gender and Income Situation}

Age is relevant to the investigation because intellectual impairment can affect people of differing ages in disparate ways (see Michaels, 1994), and since age can impact on physical activities such as the use of transportation (Topinkova, 2008; DWP, 2018a). Gender was considered as the life experiences of mentally disabled males and females can vary, e.g., with respect to degrees of economic disadvantage (Courtemanche and Turner, 2017) and/or social exclusion (Papworth Trust, 2018). Females have been found to be more likely to report a mental health problem than males (NHS, 2016). A simple question on household income was included (see the appendix) because travel can be expensive and thus an inhibiting factor on the transportation choices of some disabled people (DWP, 2018a). Also, mental health problems are more likely to be reported in lower income categories (NHS, 2016). Individuals from ethnic minorities are overrepresented in mental health statistics (MIND, 2013), but ethnicity was not explored as (i) the pilot study revealed that the respondents resented being asked this question, (ii) the volunteers asking the questions were unable to describe accurately differences in ethnicity, and (iii) it is likely that the simple question on income category would capture much of the influence of ethnicity considering that ethnic minorities are often overrepresented in lower -income groups. UK government statistics reveal that in 
2015 around 35\% of black households and 37\% of other ethnic minority households had incomes of less than $£ 400$ a week, compared with $20 \%$ of white households (DWP, 2018b). The disparities are considerably greater when household circumstances are considered (see Palmer and Kenway (2007).

\subsubsection{Effects of Presence of Other Disabilities}

It was necessary to assess the extent to which a disability interfered with a person's normal daily life. Comingled disabilities affect people's daily lives in disparate ways (Bogart, 2014) and involve varying levels of stress and anxiety. Individuals react and adapt to disability differently, with consequences for their everyday activities (Amtmann et al., 2012; Bogart, 2014). Hence, attitudes relating to a fresh transportation opportunity (such as AVs) may vary among people with compound disabilities. Individuals who believe that their disability greatly impedes their everyday lives might be favourably inclined towards a new transportation technology that significantly facilitates their capacity to travel (Forber-Pratt, Lyew, Mueller and Samples, 2017).

\subsection{Measurement of Variables}

The questions asked of the participants were brief and worded in manners appropriate for intellectually disabled people. Generalised anxiety was measured using the four items of the Hopkins Anxiety Syndrome Checklist (Parloff, Kelman and Frank, 1954) previously employed successfully by Brenes et al. (2005) to measure the construct among people with mental disabilities. In the present study a factor analysis of the responses revealed a one-factor solution (Cronbach's alpha=.88) with all items loading onto the first factor ( $\mathrm{h}>.6$ ), which explained $82 \%$ of total variance. The degree of a participant's internal locus of control was assessed via seven items based on the Pearlin Mastery Scale (Pearlin and Schooler, 1978); a scale that has been used successfully in various healthcare and disability contexts (e.g., Ecklund, Erlandsson and Hagell, 2012). The scale has been used in many countries in studies of adults with mental and physical health difficulties. The responses of the members of the present sample to the Pearlin Scale items demonstrated sound reliability and convergent validity (lambda=5.5; alpha =.88). Three intercorrelated $(\mathrm{R}=.79)$ items based on Konig and Neumayr (2017) evaluated "prior knowledge of AVs". Four items (lambda=3.3, alpha=.88) informed by Hoenig et al. (1999) and Forber-Pratt et al. (2017) was used to measure perceived intensity of disability. Following Konig and Neumayr (2017), willingness to travel in an AV was assessed through four items (lambda=3.44, alpha=.89). Apart from factual queries and unless otherwise stated all items were scored using five-point agree/disagree scales.

\subsection{Questionnaire Testing and Administration}

A draft of the questionnaire was discussed with (i) the chief executives of the two charities, (ii) a senior design architect (autonomous vehicles) at Nissan Motors USA, and (iii) a senior executive at the United Nations Convention on the Rights of Persons with Disabilities. The resulting document was then given to 30 intellectually disabled individuals drawn at random 
from the database of the first of the abovementioned charities. Twenty-two usable responses were received, which indicated the need to reword certain items. The final questionnaire (summarised in the appendix to the paper) was distributed to members of the main sampling frame through 2017 and 2018.

\section{RESULTS}

\subsection{Outcome to the STM}

A three-topic STM solution outperformed alternatives in terms of topic exclusivity (i.e., topics with words with high probabilities of appearing in one topic but low probabilities of appearing in others) and semantic coherence (i.e., individual responses within a topic containing similar words). Replies contained 36 words on average (median 22; range nine to 77). The results for the topic aggregates are given in Table 2.

\section{INSERT TABLE 2 HERE}

Topic one contained the commonest genre of response (46\%) invoked by thoughts of AVs, i.e., a sense of "freedom". AVs were seen to offer personal independence and a method of travel equal in all ways to that experienced by everyone else in the population, and to enable the participants to travel freely and conveniently without having to worry about uncooperative outsiders, Topic two (34\%) "fear" involved worries and anxieties about travelling in an AV, including safety concerns, fears of feeling unwell, feeling lost, fear of accidents, etc., while in a driverless vehicle. The third topic (20\%) concerned the respondents' “curiosity” about AVs. This dimension of attitude reflected the participants' interest in AVs and their desire to know more about them, accompanied by questions regarding their safety and reliability.

\subsection{Regression Analysis}

\section{INSERT FIGURE 1 HERE}

A structural equation regression analysis was completed to explain the topic prevalence figures of each participant on the basis of the covariates previously outlined. Within the data emerging from the structural topic model, each of the topics comprised a column of numbers containing each participant's score for that particular topic (expressed as a proportion out of 100). A person's three topic scores totalled 100. The estimated model (see Figure 1) contained "willingness to travel in an AV" as the final dependent variable, with the three topic prevalence variables as mediators and taking into account possible direct effects of the covariates on the dependent variable. The influence of "generalised anxiety", for example, is 
assumed to operate through "fear", which in turn affects willingness to travel. Similarly, "freedom" constitutes the mechanism whereby locus of control has a mediated impact on the dependent variable. The method of partial least squares was used to estimate Figure 1 as this requires no assumptions regarding variable distributions and since the investigation sought to build theory rather than test an existing theory (Hair, Sarstedt, Ringle and Mena, 2012). Outputs from the regression analysis are shown in Table 3.

\section{INSERT TABLE 3 HERE}

It can be seen from Table 3 that topic one prevalence ("freedom") depended significantly on generalised anxiety, prior knowledge of AVs, and intensity of disability. Topic two ("fear") was significantly determined by generalised anxiety, locus of control, prior knowledge, and gender. Topic three (“curiosity”) was influenced significantly by locus of control. Age and income category had no significant effects on any of the outcomes. Females tended to be more fearful of AVs than males and less curious about these vehicles. Disruptive and innovative technologies often create fear in consumers (Thierer and Hagemann, 2014). Typically, however, an initial resistance leads to gradual adaptation and eventual assimilation of a new technology into society (Thierer, 2013). Research exists to suggest that females are generally more prone to feeling anxious when it comes to trialling and adapting new technologies (Broos, 2005) and specifically vis-à-vis driving (Simon and Corbett, 1996). Lawton (1994) found that women also reported higher levels of spatial anxiety, or anxiety about environmental navigation, than did men. This is an interesting result in the context of driverless cars, as spatial navigation will in fact be less relevant to the AV experience.

People who believed that their disability greatly interfered with their daily lives placed a higher value than others on the freedom that AVs offer. The potential for driverless cars to offer mobility solutions for the disabled population has been indicated in research undertaken during the development of the technology (Dana and Mele, 2013). Desire for freedom in relation to transportation has often been observed in physically disabled communities (Bradshaw-Martin, 2012) and among non-drivers in general (Litman, 2018). Independence has the potential to support "functioning" (Bradshaw, 2014), and travel is a function that allows a disabled person to do more; a "state of being" that is clearly linked to health and well-being (Nusbaum, 2003, p.40). Individuals who reported that they possessed some knowledge of AVs scored relatively highly in the prevalence figures for freedom and curiosity, and were significantly less fearful. Participants who experienced generalised anxiety welcomed the freedom of AVs, but were more fearful. Interestingly, a study by Koo et al. (2014) found, in the context of semi-autonomous driving, that multiple simultaneous messages by automated vehicle systems caused confusion and lead to an increased anxiety level. The cause of anxiety in this instance was primarily that driving requires quick reactions and response times to deal with changing environmental situations. In the case of AVs, however, anxieties are likely to be founded on a perception of lack of control (cf. Mineka and Kelly, 1989). Indeed, this idea can be linked to another finding of the present study which suggests that individuals with high internal locus of control were on the average less fearful of AVs than the rest of the sample. Studies in "fear of flying" have shown that individuals 
who suffer from a panic disorder avoid specific situations such as flying as they know that they have no control once the aircraft takes off (McNally and Lukach, 1992).

Topic prevalence one (freedom) had a significantly positive influence on willingness to travel in AVs. Fear (topic two) had a significantly negative impact, while curiosity (topic three) did not exert a significant impact on the dependent variable. As regards the direct effects of the covariates on willingness to travel in an AV, Table three indicates that (as expected a priori) prior knowledge of AVs and intensity of disability exerted significant direct effects independently of the mediators. No other covariate had a significant influence.

\section{DISCUSSION AND CONCLUSION}

\subsection{Conclusion}

High internal locus of control reduced the probability of responses falling in the "fear" category and increased "curiosity" based replies. This outcome is compatible with the findings of prior literature on linkages between locus of control and the attitudes and behaviour of the intellectually impaired, e.g., Wehmeyer, 1993; Shopren et al., 2010. People with generalised anxiety valued the "freedom" that AVs offer, but were also more fearful than others of this new technology (cf. Navaco, 1979; Cooray and Bakala, 2005). These results suggest a liking for the privacy and independence of AVs and for the increased social interactions that might ensue from their use. Prior knowledge of AVs was a significantly positive determinant of the responses that fell in the freedom and curiosity prevalence divisions, and had a significantly negative influence on the fear dimension. Past research has noted the impact of prior knowledge on attitudes to new kinds of vehicles (e.g., electric cars) and on intentions to use them (see Moons and DePelsmacker, 2012; Rezvani et al., 2015). Age and household income situation were not associated with the probabilities of the participants' attitudes leaning towards any one of the three topics. This may be due to the fact that AVs constitute a completely new technology and hence that attitudes towards AVs are independent of whether a person is young or old, financially well-off or poor. The variable reflecting the "freedom" topic significantly increased a person's willingness to travel in an AV, whereas high values for the "fear" variable significantly reduced willingness to travel.

As regards locus of control, past studies have established that "self- efficacy expectations" can be influenced and strengthened via appropriate health-related communications (Smith, 1989, p. 230). Thus, social marketing could be used to demonstrate to intellectually disabled people who are low in internal locus of control the ease with which they will be able to understand and control AVs; the minimal effort needed to operate AVs; their simplicity of operation compared with conventional vehicles and their reliability and dependability (cf. Chung, Preveza, Papandreau and Prevezas, 2006; Jacobs-Lawson, Waddell and Webb, 2011). The significance of prior knowledge as an antecedent of all three topic prevalences demonstrates the need for manufacturers and state agencies supplying copious amounts of information on AVs to intellectually disabled groups. As expected, individuals with high intensities of disability (i.e., those needing large amounts of help with daily tasks) were more enthusiastic about the liberating aspects of AVs than others. This "freedom-inspiring" dimension of AVs could figure prominently in campaigns. Age and income category did not exert significant influences on the topic prevalences of the participants, implying that there is 
little point in manufacturers and state agencies targeting specific age groups or income classes in social marketing campaigns.

\subsection{Contributions and Implications}

Transportation systems impact extensively on personal and public health (Widener and Hatzopoulou, 2016). The present study identified several significant influences on the attitudes towards AVs of a sample of intellectually disabled people and the consequences of these attitudes for their willingness to adopt this new form of travel. This issue is important because AVs have the potential to greatly improve the lives and overall capabilities of disabled people. Bell (2017) commented that "transportation is being disrupted to its core by new technology”, and hence that "new techniques” are needed to assess the impact of (transport) automation (p. 587). The current research contributes in this respect through its use of a relatively new approach to qualitative research; structural topic modelling, which is capable of analysing rigorously people's responses to open-ended questions and is clearly valuable for assessing the views of people with intellectual disabilities.

By providing a template for the contents of AV information campaigns aimed at intellectually impaired people the outcomes to the study have implications both for manufacturers wishing to lease or sell AVs to intellectually impaired individuals (or their families) and for public policy concerning AVs. Herrmann et al. (2018) observed how governmental knowledge of disabled citizens' views on AVs will help state agencies to develop and implement policies on disability-friendly road and traffic layouts and systems. If social inclusion is to be improved in the transportation sphere then, in the words of Claypool et al. (2017), "it is imperative that a broader disability community coalesce around a constrained set of policy recommendations” (p.7). Lu et al. (2017) observed how an increased knowledge of public opinion should help government policy makers as they develop and implement policies and traffic regulations appropriate for the introduction of AVs. Once knowledge of public opinion has been obtained, state agencies will need to supply useful and persuasive information about AVs alongside the promotional communications of manufacturers, as some disabled members of the public may distrust commercial advertisements about the new technology.

\subsection{Limitations and Areas for Future Research}

A caveat applying to all qualitative research based on open-ended questions is that participants might interpret an open-ended question differently. Also one person may answer in a few words whereas another might use many sentences. Some respondents might answer a question flippantly; others might say what is on their mind at a particular instant but not reveal their underlying attitudes. (In the present study the authors physically examined each response to identify obvious absurdities, none occurring.) On the other hand, open-ended responses avoid biased responses arising from cues that are often present in research based on structured questions. STM avoids bias through allowing respondents to express their views at whatever length they decide, and the researcher does not have to impose a coding system.

Other limitations of the research are that the study was completed in a single country and included a restricted number of explanatory variables. Future investigations could replicate 
the study in other countries and might examine the influences of variables other than those included in the present research, e.g., social norms or people's housing situations. Also, the methodology applied within the present study could be used to examine the transportation situations faced by people with other types of disability, e.g., the visually impaired. The construct of "generalised anxiety" has several facets. Studies could explore the effects of various aspects of generalised anxiety on the attitudes of intellectually disabled people towards AVs. An interesting area for further research concerns the best means for informing disabled people about the benefits of driverless cars, e.g., mixtures of text and pictures, videos, games, or general direct marketing communications. Another important issue is the identification of the AV vehicle designs that will appeal to people with intellectual impairments. At present all AV prototypes are similar in appearance. Presumably, vehicle manufacturers will in the future seek to differentiate their vehicles in terms of shape, comfort level, in-car amenities, etc.

\section{End notes}

1. Intellectual disabilities embrace a "wide range of neurological disorders caused by deficits in the central nervous system which influence a person's ability to maintain, process or communicate information” (Kavale and Forness, 2000 p.239). They are usually permanent and involve a lack of the skills needed for daily living. A person with an intellectual disability is usually born with the condition, has limited intellectual functioning and lacks certain skills needed for daily living. Intellectual disability can involve (i) deficiencies in memory and concentration, reasoning and decision making, sensory and motor skills, abilities to communicate and interact with others, (ii) poor adaptive behaviour, and/or (iii) little capacity to exercise personal self-care. The domain of intellectual disability is diverse and includes learning disability. Learning disability is defined by the UK Department of Health as a significantly reduced capacity to understand new and complex information and to learn new skills, with a reduced ability to cope independently which began before adulthood (MHF, 2018). This differs from “learning difficulty” (e.g., dyslexia), which does not affect intelligence and is "supported" rather than medically treated (see MIND, 2013). Around 350,000 UK residents with a learning disability use National Health Service disability services (MHF, 2018) and between a quarter and $40 \%$ also have a mental illness (e.g., severe depression, autism, bipolar disorder, schizophrenia [NHS, 2015]). A distinction exists between a learning disability and a "mental health problem" in that the former develops in early childhood at the latest whereas the latter can occur at any time. It is relevant to observe that the number of UK people diagnosed with some form of mental illness is increasing and that an extra two million individuals are estimated to require treatment for mental illness by 2030 (NHS, 2016). About one in four UK adults will experience some form of mental illness during their lives, and one in ten will have a life-long mental health condition (DWP, 2017).

2. Currently, intellectually disabled people may drive in the UK provided they pass the normal driving test and inform the Driver and Vehicle Licencing Agency (DVLA) about their disability. (The person taking a test will be offered more time in which to complete the test, will be given a diagram of directions and allowed to follow traffic 
signs rather than verbal instructions [only two of which will be given at any one time]).

\section{References}

Alaribi, I. (2015), Design a serious game to teach teenagers with intellectual disabilities how to use public transportation, Procedia: Social and Behavioural Sciences, 176, 840-845.

Alves, m. (2017), Driven to distraction: Sustainable road safety and the impact of autonomous driving on vulnerable users, ?, Journal of Transport and Health, 7 (supplement), S4, 587.

Amtmann, D., Bamer, A. Cook, K., Askew, R., Noonan, V. and Brockway, J. (2012), UW-SES: A new self-efficacy scale for people with disabilities, Archives of Physical Medicine and Rehabilitation. 93 (10), 1757-1765.

Anxiety UK (2018), Anxiety Conditions, Manchester, Anxiety UK, https.anxiety.org.uk. APA (American Psychiatric Association) (2000), Diagnostic and Statistical Manual of Mental Disorders, Fourth Edition, Washington DC, APA.

Bazilinskyy, P., Kyriakidis, M. and de Winter, J. (2015), An international crowdsourcing study into people's statements on fully automated driving, Procedia Manufacturing, 3, 25342542.

Bell, A. (2017). How will walking survive the driverless car?, Journal of Transport and Health, 7 (supplement), S4, 587.

Bogart, K. (2014), The role of disability self-concept in adaptation to congenital or acquired disability, Rehabilitation Psychology, 59 (1), 107-115.

Bradshaw-Martin, H. (2012), Defining Enhancement, Disability and Therapy: How Technology Affects Identity and the Ethical Implications of This, PhD Thesis, University of Bristol.

Bradshaw-Martin, H. and Easton, C. (2014), Autonomous or "driverless" cars and disability: A legal and ethical analysis, European Journal of Current Legal Issues, 20 (3), Web: www. jcli.org/article/view/344/471.

Brenes, G., Guralnik, J., Williamson, J., Fried, L. and Penninx, B. (2005), Correlates of anxiety symptoms in physically disabled older women, American Journal of Geriatric Psychiatry, 13 (1), 15-22.

Broos, A. (2005), Gender and information and communication technologies (ICT) anxiety: Male self-assurance and female hesitation, CyberPsychology and Behavior, 8 (1), 21-31.

Butcher,L. (2018), Access to Transport for Disabled People, House of Commons Briefing Pare CBP 601, London, House of Commons.

Chapman, L. (2016), What do self-driving vehicles mean for disabled travellers? Disabled World, 19 December 2016, www.disabled-world.com. 
Chiteji, N. (2010), Time preference, noncognitive skills and wellbeing across the life course: do noncognitive skills encourage healthy behaviour? American Economic Review, 100 (2), 200-204.

Chung, M., Preveza, E., Papandreau, K. and Prevezas, N. (2006), Spinal cord injury, posttraumatic stress and locus of control among the elderly, Psychiatry: Interpersonal and Biological Processes, 69 (1), 69-80.

Claypool, H., Bin-Nun, A. and Gerlach, J. (2017), Self-driving Cars: The Impact on People with Disabilities, Boston, Ruderman.

Cooray, S. and Bakala, A. (2005), Anxiety disorders in people with learning disabilities, Advances in Psychiatric Treatment, 11 (5), 355-361.

Cortright, L. (2016), How Much will AVs Cost? Portland Oregon, City Observatory, cityobservatory.org.

Courtemanche, A. and Turner, L. (2017), Intellectual disability: Gender and sex differences, in A. Wenzel (Ed.), The Sage Encyclopaedia of Abnormal and Clinical Psychology, Thousand oaks CA, Sage, pp. 1844-1845.

Dana M. and Mele, J. (2013), The Quasi-Autonomous Car as an assistive device for blind drivers: Overcoming liability and regulatory barriers, Syracuse Science and Technology Law Reporter, 26 (1), 28-39.

DoH (Department of Health (2011), Public Health, Adult Social Care and the NHS: Mental Health, London Department of Health, ww.dh.uk/en/Healthcare/Mentalhealth.

Doray, S. and Burke, P. (2018), On the road again: The barriers and benefits of automobility for people with disability, Transportation Research (A), 107, 229-245.

Dorr, A. (2016), Technology blindness and temporal imprecision: Rethinking the long term in an era of accelerating technological change, Foresight, 18 (4), 391-413.

DoT (Department of Transport (2015), The Pathways to Driverless Cars, London, Department of Transport, https://assets.publishing.service.gov.uk.

DWP (Department of Work and Pensions) (2017), Official Statistics: Disability Facts and Figures, London, Department of Work and Pensions, www.gov.uk.org.

DWP (Department of Work and Pensions) (2018a), Family Resources Survey 2016/17, London, Department of Work and Pensions, www.gov.uk.org.

DWP (Department of Work and Pensions) (2018b), Family Resources Survey 2014/15: Ethnicity, London, Department of Work and Pensions, www.ethnicity-facts-figures.service. gov.uk.

Easton, C. (2014), Driverless cars could change lives for disabled people, if we let them, The Conversation, 13 August 2014, Lancaster, Lancaster University, https://theconversation.com.

Eckland, M., Erlandsson, L. and Hagell, P. (2012), Psychometric properties of a Swedish version of the Pearlin Mastery scale in people with mental illness and healthy people, Nordic Journal of Psychiatry, 66 (6), 1-29. 
Egbue, O. and Long, S. (2012), Barriers to widespread adoption of electric vehicles: An analysis of consumer attitudes and perceptions, Energy Policy, 48, 717-729.

Forber-Pratt, A., Lyew, D., Mueller, C. and Samples, L. (2017), Disability identity development: A systematic review of the literature, Rehabilitation Psychology, in press website.

Garrido-Cumbrera, M., Ruiz, D., Brace, O. and Lara, E. (2018), Exploring the association between urban sprawl and mental health, Journal of Transport and Health, in press website.

Gora, P. and Rub, I. (2016), Traffic models for self-driving connected cars, Transportation Research Procedia, 14, 2207-2216.

Gosling, S. (2017), Feelings, Emotions and the Car, Amsterdam, Elsevier.

Gupta, S. and Cope, A. (2016), Mental Health and Transport Summit Report, London, Anxiety UK.

Haboucha, C., Ishaq, R. and Shiftan, Y. (2017), User preferences regarding autonomous vehicles, Transportation Research (C), 78, 37-49.

Hague, A., Lee, D., Shaw, C., Hawthorne, M., Chamberlin, S., Newman, W., Clarke, Z. and Beail, N. (2013), What makes people with a learning disability happy and satisfied with their lives? An inclusive research project, Journal of Applied Research in Intellectual Disabilities, 26 (1), 26-33.

Hair, J., Sarstedt, M., Ringle, C. and Mena, J. (2012), Assessment of the Use of Partial Least Squares Structural Equation Modelling in Marketing Research, Journal of the Academy of Marketing Science, 40 (3), 414-433.

Halsey, A. (2017), Driverless cars promise far greater mobility for the elderly and people with disabilities, Washington Post, 23 November 2017, www.washingtonpost.com.

Henderson, S. and Golden, M. (2015), Self-driving Cars: Mapping Access to a Technology Revolution, Washington DC, National Council on Disability.

Herrmann, A., Brenner, W. and Stradler, R. (2018), Autonomous Driving: How the Driverless Revolution Will Change the World, Bradford, Emerald.

Hirschman, E. and Stern, B. (1998), Consumer behaviour and the wayward mind: The influence of mania and depression on consumption, Advances in Consumer Research, 25, 421-427.

Hoenig, H., Branch, L., McIntyre, L., Hoff, J. and Horner, R. (1999), The validity in persons with spinal cord injury of a self-reported functional measure derived from the functional independence measure, Spine, 24 (6), 539-543.

Huang, J. and Ford, J. (2012), Driving locus of control and driving behaviours: Inducing change through driver training, Transportation Research (F): Traffic Psychology and Behaviour, 15 (3), 358-368.

Hulse, L., Xie, H. and Galea, E. (2018), Perceptions of autonomous vehicles: Relationships with road users, risk, gender and age, Safety Science, 102, 1-13. 
Jacobs-Lawson, J., Waddell, E. and Webb, A. (2011), Predictors of health locus of control, Current Psychology, 30, 173-183.

Kavale, K. and Forness, R. (2000), What definitions of learning difficulties say and don't say: A critical analysis, Journal of Learning Disability, 33, 239-256.

Konig, M. and Neumayr, L. (2017), Users' resistance towards radical innovations: The case of the self-driving car, Transportation Research (F), 44, 42-52.

Koo, J., Kwac, J., Ju, W., Steinert, M., Leifer, L. and Nass, C. (2015), Why did my car just do that? Explaining semi-autonomous driving actions to improve driver understanding, trust, and performance, International Journal on Interactive Design and Manufacturing, 9 (4), 269-275.

Lawton, C. (1994), Gender differences in way-finding strategies: Relationship to spatial ability and spatial anxiety, Sex Roles, 30 (11-12), 765-779.

Litman, T. (2017), Autonomous Vehicle Implementation Predictions, Victoria, Canada, Victoria Transport Policy Institute.

Lu, Z., Du., R., Dunham-Jones, E., Park, H. and Crittendon, J. (2017), Data-enabled public preferences inform integration of AVs with transport-oriented development in Atlanta, Cities, 63, 118-127.

McElroy, J., Hendrickson, A., Townsend, A. and DeMarie, S. (2007), Dispositional factors in internet use: Personality versus cognitive style, MIS Quarterly, 31 (4), 809-820.

McNally, R. and Lukach, B. (1992), Are panic attacks traumatic stressors? American Journal of Psychiatry, 149, 824-826.

Matson, J., Gardner, W., Coe, D. and Sovner, R. (1991), A scale for evaluating emotional disorders in severely and profoundly mentally retarded person: Development of the Diagnostic Assessment for the Severely Handicapped (DASH) scale, British Journal of Psychiatry, 159, 404-409.

MHAG (Mental Health Action Group) (2011), Mental Health and Public Transport: A Report by the Mental Health Action Group, Derby, MHAG, www.derbyshiremind.org.uk.

MHF (Mental Health Foundation) (2015), Fundamental Facts about Mental Health, London, Mental Health Foundation, www.mentalhealth.org.uk.

MHF (Mental Health Foundation) (2017), Learning Disability Statistics: Mental Health Problems, London, MHF, www.mentalhealth.org.uk.

MHF (Mental Health Foundation) (2018), Learning Disabilities, London, MHF, www.mentalhealth.org.uk.

Michaels, C. (1994), Transition Strategies for Persons with Learning Disabilities, San Diego, Singular Press.

MIND (2013), Types of Mental Health Problems, London, MIND, www.mind.org.

Mindham, J. and Espie, C. (2003), Glasgow anxiety scale for people with an intellectual disability (GAS-ID): Development and psychometric properties of a new measure for use 
with people with mild intellectual disability, Journal of Intellectual Disability Research, 47 (1), 22-30.

Mineka, S. and Kelly, K. (1989), The relationship between anxiety, lack of control and loss of control, in A. Steptoe and A. Appels (Eds.), Stress, Personal Control and Health (pp. 163191), Oxford, John Wiley \& Sons.

Möller, A., Nortje, C. and Helders, S. (1998), Irrational cognitions and the fear of flying, Journal of Rational-emotive and Cognitive-behavior Therapy, 16 (2), 135-148.

Moons, I. and De Pelsmacker, P. (2012), Emotions as determinants of electric car usage intention, Journal of Marketing Management, 28 (3/4), 195-237.

Morris, J. (2017), Are we going too fast on driverless cars? Science, 359 (6), 380-386.

Nakamura, F. and Ooie, K. (2017), A study on mobility improvement for intellectually disabled student commuters, International Association of Traffic and Safety Sciences Research, 41, 74-81.

Navaco, R., Stokols, D., Campbell, J., and Stokols, J. (1979), Transportation stress and community psychology, American Journal of Community Psychology, 7 (4), 361-380.

NHS (National Health Service) (2015), What is Learning Disability? London, NHS, www.nhs.uk/livewell.

NHS (National Health Service) (2016), Adult Psychiatric Morbidity Survey: Survey of Mental Health and Wellbeing, England 2014, London, NHS Digital, webarchive.nationalarchives.gov.uk.

NHS (National Health Service) (2018), Generalised Anxiety Syndrome in Adults, London, NHS, www.nhsuk/conditions/generalised-anxiety-disorders.

NHS (National Health Service) (2018), Health and Care of People with Learning Disabilities 2016 to 2017, London, NHS Digital, https//digital.nhs.uk/data-and-information.

NDA (National Disability Authority) (2009), Ethical guidance for research with people with disabilities, Disability Research Series 13, Dublin, NDA.

Nind, M. (2008), Conducting Qualitative Research with People with Learning, Communication and Other Difficulties: Methodological Challenges, ESRC National Centre for Research Methods Review Paper, NCRM / 012, Swindon, Economic and Social Research Council.

Nussbaum, M. (2003), Capabilities as fundamental entitlements: Sen and social justice Feminist Economics, 9 (2-3) 33-59.

OECD (Organisation for Economic Cooperation and Development) (2009), Cognitive Impairment, Mental Health and Transport, Paris, OECD.

Oldham, P. (2016), Autonomous and Driverless Cars Report, London, Institute of Mechanical Engineers. 
Özkan, T. and Lajunen, T., 2005, Multidimensional traffic locus of control Scale (T-LOC): factor structure and relationship to risky driving, Personality and Individual Differences, 38 (3), 533-545.

Palmer, G. and Kenway, P. (2007), Poverty Rates Among Ethnic Groups in Great Britain, York, Joseph Rowntree Foundation.

Papworth Trust (2018), Disability in the United Kingdom: Facts and Figures, Brentwood Mdx., Papworth Trust.

Park, J., Faulkner, J. and Schaller, M. (2003), Evolving disease avoiding processes and contemporary anti-social behaviour: Prejudicial attitudes and avoidance of people with physical disabilities, Journal of Nonverbal Behaviour, 27 (2), 65-87.

Parloff, M., Kelman, H. and Frank, J. (1954), Comfort, effectiveness, and self-awareness as criteria for improvement in psychotherapy, American Journal of Psychiatry, 3, 343-351.

Payne, A., Frow, P. and Eggert, A. (2017), The customer value proposition: Evolution, development, and application to marketing, Journal of the Academy of Marketing Science, 45, 467-489.

Payre, W., Cestac, J. and Delhomme, P. (2014), Intention to use a fully automated car: Attitudes and a-priori acceptability, Transportation Research (F), 27, 252-263.

Pearlin, L. and Schooler, C. (1978), The structure of coping, Journal of Health and Social Behaviour, 19, 2-21.

Reid, K., Smiley, E. and Cooper, S. (2011), Prevalence and association of anxiety disorders in adults with intellectual difficulties, Journal of Intellectual Disability Research, 55 (2), 172181.

Rezvani, Z., Jansson, J. and Bodin, J. (2015), Advances in consumer vehicle adoption research: A review and research agenda, Transportation Research D, 34, 122-136.

Roberts, M., Stewart, B. and Tingley, D. (2018), STM: An R package for the Structural Topic Model. (Free software for STM estimation.) www.structuraltopicmodel.com.

Roberts, M., Stewart, B., Tingley, D., Lucas, C., Leder-Luis, J., Gadarian, S., Albertson, B. and Rand, D. (2014), Structural topic models for open ended survey responses, American Journal of Political Science, 58 (4), 1064-1082.

Robertson, J. (2003), An Excess of Phobias and Manias, Los Angelis, Scribe Publishers.

Ross, E. and Oliver, C. (2003), Preliminary analysis of the psychometric properties of the mood, interest and pleasure questionnaire (MIPQ) for adults with severe and profound learning disabilities, British Journal of Clinical Psychology, 42, 81-93.

Rotter, J. (1966), Generalized expectancies for internal versus external control of reinforcement, Psychological Monographs: General and Applied, 80 (1),1-28.

Sherva, E. and Bakala, A. (2018), Anxiety disorders in people with learning disabilities, Advances in Psychiatric Treatment, 11 (5), 355-361. 
Shopren, K., Bovaird, J., Palmer, S. and Wehmeyer, M. (2010), Locus of control in students with intellectual disability, learning disabilities, and no disabilities: A latent growth curve analysis, Research and Practice for Persons with Severe Disability, 35 (3/4), 80-92.

Simon, F. and Corbett, C. (1996), Road traffic offending, stress, age, and accident history among male and female drivers, Ergonomics, 39(5), 757-780.

Smith, R (1989), Effects of coping skills training on generalised self-efficacy and locus of control, Journal of Personality and Social Psychology, 56 (2), 228-233.

Soderlund, M. and Gunnarsson, J. (2000), Customer familiarity and its effects on satisfaction and dissatisfaction, SSE/EFI Working Paper Series in Business Administration No. 2000:2, Stockholm School of Economics, Sweden.

Spitzer, R., Kroenke, K. and Williams, J. (2006), A brief measure for assessing generalised anxiety syndrome: The GAD 7, Archives of Internal Medicine, 166 (10), 1092-1097.

Tanzman, B. (1993), An overview of mental health consumers' preference for housing and support services, Hospital and Community Psychiatry, 44 (5), 450-455.

Thierer, A. (2013), Technopanics, threat inflation, and the danger of an information technology precautionary principle, Minnesota Journal of Law, Science, and Technology, 14 (1), 312-50.

Thierer, A. and Hagemann, R. (2015), Removing roadblocks to intelligent vehicles and driverless cars, Wake Forest Journal of Law and Policy, 5, 339-349.

Topinkova, E. (2008), Aging, disability and frailty, Annals of Nutrition and Metabolism, 52, 6-11.

Vogel, N. (2006), Not marketing to people with disabilities? You're missing out, Ad Age, 31 July 2006, pp. 1-4, www.adage.com.

Wehmeyer, M. (1993), Factor structure and construct validity of a locus of control scale with individuals with mental retardation, Educational and Psychological Retardation, 53 (4), 1055-1066.

Widener, M. and Hatzopoulou, M. (2016), Contextualising research on transportation and health: A systems perspective, Journal of Transport and Health, 3, 232-239.

Williams, E., Tillin, T., Whincup, P., Forouhi, N. and Chaturvedi, N. (2012), Ethnic differences in disability prevalence and their determinants studied over a 20-year period: A cohort study, PloS One, 7 (9), e45602, www.journals.plos.org.

Wood, W. and Letak, J. (1982), A mental-health locus of control scale, Personality and Individual Differences, 3 (1), 84-87. 


\section{APPENDIX: THE QUESTIONNAIRE}

\section{Hopkins Anxiety-proneness Scale}

4-point scale: 4=extremely often; $1=$ not at all

I feel fearful

I feel nervous and shaky inside

I feel tense or keyed up

I spend a lot of time worrying about things

\section{Pearlin Mastery Scale}

There is really no way I can solve some of the problems I have Sometimes I feel that I'm being pushed around in life I have little control over the things that happen to me I can do just about anything I really set my mind to I often feel helpless in dealing with the problems of life What happens to me in the future mostly depends on me.

There is little I can do to change many of the important things in my life

\section{Willingness to Travel in an AV}

I would be willing to travel in an AV

I would not want to travel in an AV for everyday use, only for special occasions I would be delighted to travel in an AV

The prospect of travelling in an AV does not appeal to me at all 
Figure 1. Regression Analysis

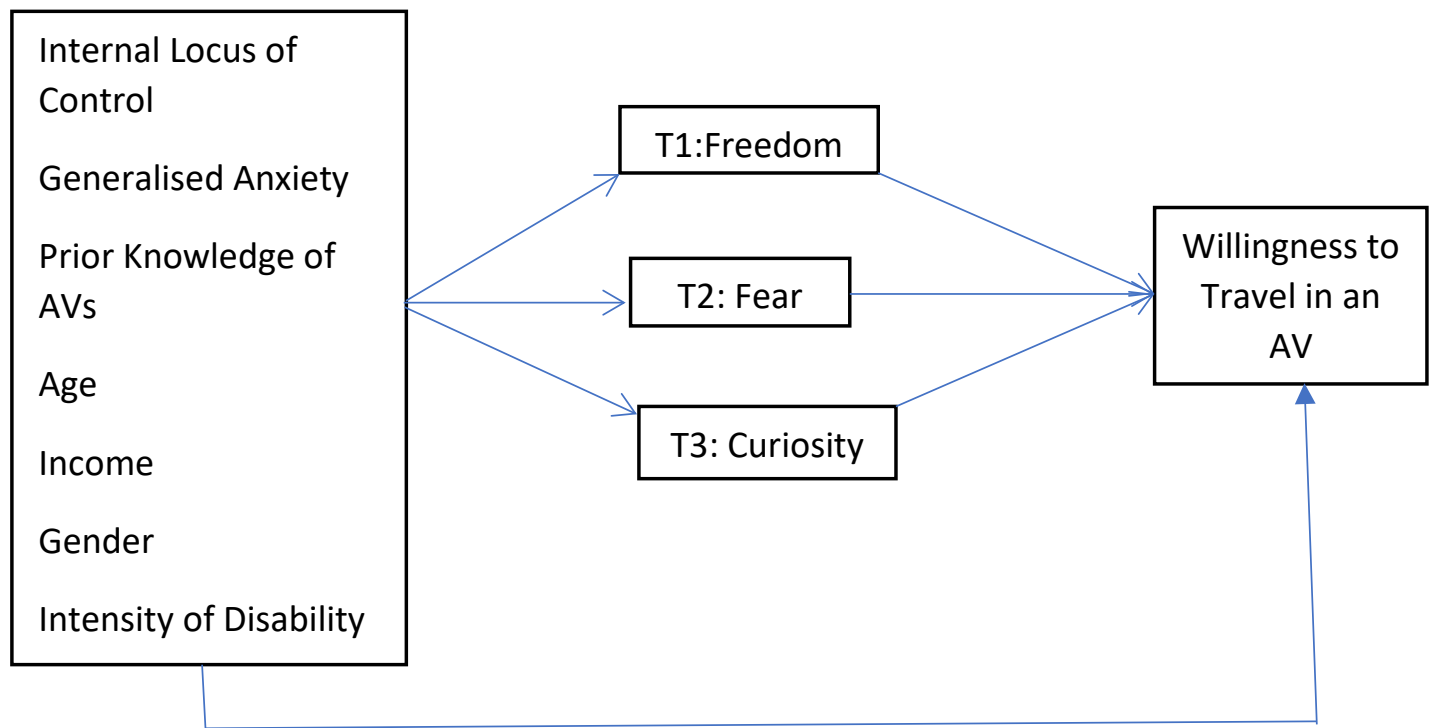


Table 1. Characteristics of Sample Members (177 Respondents)

\begin{tabular}{|l|l|}
\hline Age (median) & 39 years \\
\hline Gender (\% female) & $60 \%$ \\
\hline Income Level & $25 \%$ \\
$\quad$ Below average & $50 \%$ \\
About average & $25 \%$ \\
\hline Above average & $14 \%$ \\
\hline Frequency of use of transportation & $22 \%$ \\
$\quad$ Occasional & $64 \%$ \\
Frequent & $87 \%$ \\
\hline Daily & \\
\hline Location urban/rural (\% urban) & $62 \%$ \\
\hline How long have you been disabled? & $8 \%$ \\
$\quad$ All my life & $13 \%$ \\
Five years or less & $17 \%$ \\
Between six and 15 years & \\
More than 16 years but not all my life & $38 \%$ \\
\hline How do you usually travel? & $67 \%$ \\
$\quad$ I drive myself & $11 \%$ \\
I get lifts from family friends & $50 \%$ \\
I get taxis & $68 \%$ \\
I use public transport & \\
I walk or cycle & $18 \%$ \\
\hline Intensity of disability (Percentage of responses in agree/strongly & $18 \%$ \\
categories) & $46 \%$ \\
I need a lot of help to move around inside my house & $70 \%$ \\
I need a lot of help for self-care (dressing, bathing, etc.) & \\
I need a lot of help with shopping, housework, laundry, etc. \\
I can handle most things of a physical nature that come my \\
way (Reverse scored) & $89 \%$ \\
\hline Prior Knowledge of AVs (Percentage of responses in & \\
agree/strongly categories) & \\
I am largely ignorant of AVs & \\
I have not read or seen much information about AVs & \\
I am quite familiar with the idea of driverless vehicles & \\
(Reverse scored) & \\
\hline
\end{tabular}




\section{Table 2. Topic Prevalence}

Topic 1. Label: Freedom. Average Prevalence $=46 \%$.

Most Common Words and Phrases*: independent, free, travel like everyone else, private, in my own space, don't have to worry about rude people, many choices.

Representative comment: Can't wait - I will travel just like everybody else. No worries about where or when I can go. I'm thrilled to be free and can travel on my own without asking anybody.

Topic 2. Label: Fear. Average Prevalence $=34 \%$.

Most Common Words and Phrases*: afraid, accidents, worried, left helpless, shaky, feeling unwell while travelling, unsafe.

Representative comment: They really scare me stiff. Other cars will bump into them all the time because they are not controlled by anybody and they are not safe at this moment. I would feel ill if I had to travel in one.

Topic 3. Label: Curiosity. Average Prevalence $=20 \%$.

Most Common Words and Phrases*: interesting, unknown, want to know more, like to try one, makes me think, a puzzle, will they make my life better?

Representative comment: Brilliant idea but untried so far. I would love to know a lot more about what they can do for someone like me. I need to know if they are safe and affordable.

*The words and phrases shown are summary interpretations of the many words and phrases used to describe these feelings. 
Table 3. Parameter Estimates

\begin{tabular}{|c|c|c|c|c|}
\hline & \multicolumn{4}{|c|}{ Dependent Variables } \\
\hline & $\begin{array}{l}\text { Topic } 1 \\
\text { Prevalence } \\
\text { "Freedom” }\end{array}$ & $\begin{array}{l}\text { Topic } 2 \\
\text { Prevalence } \\
\text { "Fear" }\end{array}$ & $\begin{array}{l}\text { Topic } 3 \\
\text { Prevalence } \\
\text { "Curiosity" }\end{array}$ & $\begin{array}{l}\text { Willingness to } \\
\text { Travel in an AV }\end{array}$ \\
\hline $\begin{array}{l}\text { Explanatory } \\
\text { variables }\end{array}$ & & & & \\
\hline $\begin{array}{l}\text { Topic } 1 \\
\text { Prevalence } \\
\text { (Freedom) }\end{array}$ & & & & $.43(4.44)^{* *}$ \\
\hline $\begin{array}{l}\text { Topic } 2 \\
\text { Prevalence } \\
\text { (Fear) }\end{array}$ & & & & $-.38(4.06)^{* *}$ \\
\hline $\begin{array}{l}\text { Topic } 3 \\
\text { Prevalence } \\
\text { (Curiosity) }\end{array}$ & & & & $.16(1.07)$ \\
\hline $\begin{array}{l}\text { Internal Locus } \\
\text { of Control }\end{array}$ & $.09(0.12)$ & $-.33(3.33)^{* *}$ & $.33(3.44)^{*}$ & $.11(1.13)$ \\
\hline $\begin{array}{l}\text { Generalised } \\
\text { Anxiety }\end{array}$ & $.37(5.21)^{* *}$ & $.46(5.50)^{* *}$ & $.12(1.38)$ & $.13(1.47)$ \\
\hline $\begin{array}{l}\text { Prior } \\
\text { Knowledge of } \\
\text { AVs }\end{array}$ & $.29(2.81)^{* *}$ & $-.30(3.08)^{* *}$ & $.25(2.40)^{*}$ & $.25(2.99)^{* *}$ \\
\hline $\begin{array}{l}\text { Intensity of } \\
\text { disability }\end{array}$ & $.25(2.79)^{* *}$ & $.11(1.49)$ & $.15(1.67)$ & $.23(2.33)^{*}$ \\
\hline Age & $.01(0.06)$ & $-.10(1.05)$ & $.13(1.38)$ & $.05(0.45)$ \\
\hline $\begin{array}{l}\text { Income } \\
\text { Category }\end{array}$ & $.14(1.55)$ & $.07(0.09)$ & $-.10(0.99)$ & $-.07(0.06)$ \\
\hline $\begin{array}{l}\text { Gender } \\
\text { (male=1; } \\
\text { female=2) }\end{array}$ & $.12(1.44)$ & $.40(3.98)^{* *}$ & $.12(1.60)$ & $.09(0.99)$ \\
\hline $\mathrm{R}^{2}$ & .40 & .46 & .18 & .43 \\
\hline
\end{tabular}

T-values in parentheses. ${ }^{*}$ Denotes significance at the .05 level or below. ${ }^{*}$ Denotes significance a the .001 level or below. 